\title{
Potential Explanations for the Limited Empirical Evidence in Support of Theory in Health Promotion
}

Kevin M Cummins ${ }^{1,2,3,4^{*}}$, Eileen V Pitpitan ${ }^{1,2}$, María Luisa Zúñiga², Mark B Reed², and Sandra A Brown ${ }^{3}$

${ }^{1}$ Joint Doctoral Program in Interdisciplinary Research on Substance Use, Division of Infectious Diseases and Global Public Health, Department of Medicine, University of California San Diego, La Jolla, CA, USA. ${ }^{2}$ School of Social Work, San Diego State University, San Diego, CA, USA

${ }^{3}$ Departments of Psychology and Psychiatry, University of California San Diego, La Jolla, CA, USA.

${ }^{4}$ Department of Family Medicine and Public Health, University of California San Diego, La Jolla, CA, USA.

* Correspondence:

Kevin M Cummins

Department of Psychology

University of California San Diego

9500 Gilman Drive

La Jolla, CA 92093-0109

858.295 .2763

kcummins@ucsd.edu

kcummins760@twitter

ORCID: 0000-0003-1982-7836 


\section{Potential Explanations for the Limited Empirical Evidence in Support of Theory in Health Promotion}

Persuasive arguments for the use of theory have been influential in health promotion. The use of theory is expected to improve intervention outcomes and facilitate scientific advancement. Current empirical evaluations on the benefits of theory have not consistently demonstrated strong effects. A lack of resolution on this matter can be attributable to several features of the current body of evidence. First, the use of theory may be confounded with other features that impact health-related outcomes. Second, the field conflates models and theories. Lastly, all theories are treated the same regardless of their evidentiary status. Adopting a refined characterization of theory would leave future investigations less vulnerable to the challenges observed in the current body of evidence.

Keywords: health promotion, health psychology, health behavior, paratheoretical research, scientific representation, philosophy of science 
There is nothing as practical as a good theory.

-Kurt Lewin (McCain, 2015, p. 1)

Field theory can hardly be called a theory in the usual sense.

-Kurt Lewin (Lewin, 1951, p. 45)

\section{Introduction}

The development and application of theory holds a prominent role in health promotion (HP). It has been suggested that the most efficient and effective intervention efforts will be facilitated by theory utilization (Albada, Ausems, Bensing, \& van Dulmen, 2009; Datta \& Petticrew, 2013; Glanz \& Bishop, 2010; Lippke \& Ziegelmann, 2008; Noar, Benac, \& Harris, 2007; Michie, Johnston, Francis, Hardeman, \& Eccles, 2008). This justifies the valuation of work that includes an exposition of a project's theoretical basis. It has even been stated that leveraging theory is a necessary criterion for evidence-informed HP (Bartholomew Eldredge et al., 2016, p. 7; DiClemente, Crosby, \& Kegler, 2009, p. 10).

The evidence for superior outcomes from the theoretical grounding of interventions and related research programs has been mixed. Based on a body of literature reviews published in the first decade of the 2000s, it was concluded that the application of theory was beneficial to the field of HP (Glanz \& Bishop, 2010). However, a newer synthesis was more equivocal (Michie, West, Campbell, Brown, \& Gainforth, 2014). Additionally, a recent meta-analysis of physical activity interventions failed to find support for theory-informed approaches (Lock, Post, Dollman, \& Parfitt, 2020). Thus, the current empirical body of work evaluating the benefit of theory has not been convincing enough to disquiet debate over the importance of theory in health promotion (e.g., Hagger \& Weed, 2019).

There are other motivations that are not directly tied to the empirical literature on health 
behavior outcomes. For example, one motivation revolves around the framing of research questions and hypotheses (Krieger \& Zierler, 1996). Public health operates at the intersection of social, psychological, and biological processes across multiple ecological scales. Scientists' theoretical lenses are particularly likely to vary at the intersections. Researchers benefit from being aware of and understanding each other's underlying assumptions. Communicating the suite of underlying assumptions used to justify and interpret a study in a compact and standardized manner is facilitated by the declaration of a cognitive allegiance to a particular theory (Glanz, 2005).

Perhaps, the most prominent and tangible motivation to use theory is to access a menu of target constructs for measurement and intervention (Crosby, Kegler, \& DiClemente, 2009; Glanz, Rimer, \& Viswanath, 2015; Michie \& Prestwich, 2010; Nigg, Allegrante, \& Ory, 2002; Noar \& Zimmerman, 2005; Michie, West, Campbell, Brown, \& Gainforth, 2014). Theories can be distilled to a list of determinants of a given health behavior, many of which have a specified position in a putative causal pathway of a behavioral outcome. These constructs are treated as hypothesized mediators of health behaviors (Michie \& Prestwich, 2010). It is argued that plugging theory-housed constructs into a study has the benefit of access to a regimented system for intervention design (Michie \& Prestwich, 2010). This can be facilitated through the use of matrices of intervention components that map onto specific theory-based constructs (Michie et al., 2008). Thus, theory facilitates understanding of related behaviors, providing targets and strategies for interventionists (Bartholomew Eldredge et al., 2016; Glanz, 2005; Michie et al., 2008).

The use of theoretical constructs is also considered beneficial at the level of the whole discipline. It is argued that the inclusion of these theory-housed constructs facilitates the evaluation of theory, which improves the empirical basis for theory generalization and for making theory amendments (Michie \& Prestwich, 2010). The resultant refinement of theory further strengthens the field's knowledge base (Glanz, Rimer, \& Viswanath, 2015). It follows that theory modification can lead to changes in future research directions and clinical practice (Glanz \& Bishop, 2010). 
Beyond housing a pool of related constructs, Goodson provides a set of benefits for “theoretical thinking” (Goodson, 2010, p. 23-30). Pivoting one's approach on theory provides perspective, guidance on ethics, defense against hegemony, provision of direction for, and structuring of research activities (Goodson, 2010). Goodson also recognizes that it builds the scientific knowledge base (Goodson, 2010). Further, obtaining blueprints for prediction and control of healthrelated outcomes is also included in Goodson's general presentation (Goodson, 2010).

An implicit and distal motivation for the use of theory is related to the practice of science. A central aim of science is the construction of theories (Achinstein, 1968). In many scientific fields, the attainment of trusted scientific theory has resulted in the availability of engineering tools useful for interventions. Such tools would be eminently useful in HP. Given the limited resources and time sensitivity related to many public health concerns, running screening studies on multitudes of intervention strategies for every problem is not feasible. A reasonable aspiration is to hold a theory that informs us as to which tools to apply, without having to start from scratch for each problem that arises. Harré wrote, "Theories are the crown of science, for in them our understanding of the world is expressed" (Harré, 2004, p. 75). Unfortunately, this statement might not apply to HP and this may help explain why empirical support for the use of theory has been inconsistent. As will be discussed below, the form of HP theories differs from other sciences. This has not been adequately recognized and incorporated into the evaluation of theory in health promotion.

\section{Objective}

The aim of this paper is to outline several possible explanations for the absence of a conclusive body of work that supports the use of theory in health promotion. It is hoped that compiling and elaborating on these explanations will motivate researchers to consider and address these factors as potential sources of error and interpretation challenges when evaluating and conducting investigations on theory. The explanations can be categorized into four groups: challenges related to 
study design, poor discrimination among levels of theory utilization, conflation of models and theory, and the pooling of theory status. In the context of the current evidence base, the last three can be considered contributors to measurement error.

\section{Study Designs}

Current evaluations primarily rely on comparing patterns across studies. HP's core body of original research is not designed to evaluate the use of theory (cf. Reback, Fletcher, Shoptaw, \& Mansergh, 2015). Typically, meta-analyses on this topic are predominantly built from the effect estimates obtained through the synthesis of individual studies contributing estimates of the overall effect of the treatment to the meta-analysis, rather than individual studies contributing within-study estimates of the unique contribution of theory (e.g., Prestwich et al., 2014). Most of the analyses relevant to the original reports' topic are not specifically designed to evaluate the effects of using theory, and consequently do not have multiple arms, or exposures, where the use of theory is a variable. Because the core of the evidence that is relied upon is based on the comparison of theory effects in metaanalyses of functionally single-arm studies, there is a potential for substantial confounding to influence findings on this topic.

Key confounders of concern are the quality of the overall study design, the intervention features that are not addressed by theory, and the use of prior knowledge in designing interventions. Among reviewed studies of cancer screening, all studies failing to invoke theory in the research report scored the lowest on a structured study quality scale (Noar et al., 2007; cf. Albada et al., 2009). There is also potential confounding between projects that invoke theory and the type of care that is taken to construct and execute an intervention (Glanz \& Bishop, 2010). Assessment of benefits for modifying ultimate behavioral targets is further clouded because no accounting is made for differences in the potency of interventions to modify directly targeted constructs. For some health behaviors, the success of the intervention is related to dosage (Haller et al., 2016). Further, the same content delivered via different modalities or interventionists can affect potency (Cadigan et al., 2015; 
Carey, Scott-Sheldon, Carey, \& DeMartini, 2007; Meier, Barrowclough, \& Donmall, 2005; Project MATCH Research Group, 1998). Inclusion of targeted and proximal mediators in the measurement regime of an intervention study can assist in gauging the potency and play a role in explaining the success, or failure, of an intervention (Nigg et al., 2002; Rothman, 2011). The use of theory does not immunize an intervention study from poor design or execution, so comparisons across studies present interpretation challenges. The effects could attenuate or accentuate the outcome comparisons between theory and non-theory anchored interventions.

The most important confounder may be difficult to disentangle under the field's current approach to its treatment of theory. Because of the emphasis on using theory, the field has a propensity to wrap its knowledge into theories; there may be few opportunities to cleanly compare an intervention that is informed by prior research without its evidence-base coinciding with the knowledge that has incorporated in published theories. Newly identified determinants may be added to a theory. A notable example is the addition of perceived behavioral control to the Theory of Reasoned Action (Ajzen, 2011). Another example is the Health Belief Model (HBM), which is included in the list of theories found in a recently developed ontology-based modeling system designed to assist in the identification, description, and comparison of theories relevant to health behaviors (Hale et al., 2020). The supplementation of a self-efficacy construct to the original formulation of the HBM was in recognition of the importance of this construct as an important determinant of health behavior (Rosenstock, Strecher, \& Becker, 1988; Norman \& Brain, 2005). It may be difficult to distinguish between a study that is informed by theory and one that is informed by a thorough literature search. Because of this, the field should give the greatest deference to evidencebased on original research specifically designed to address the question of theory's benefit. 


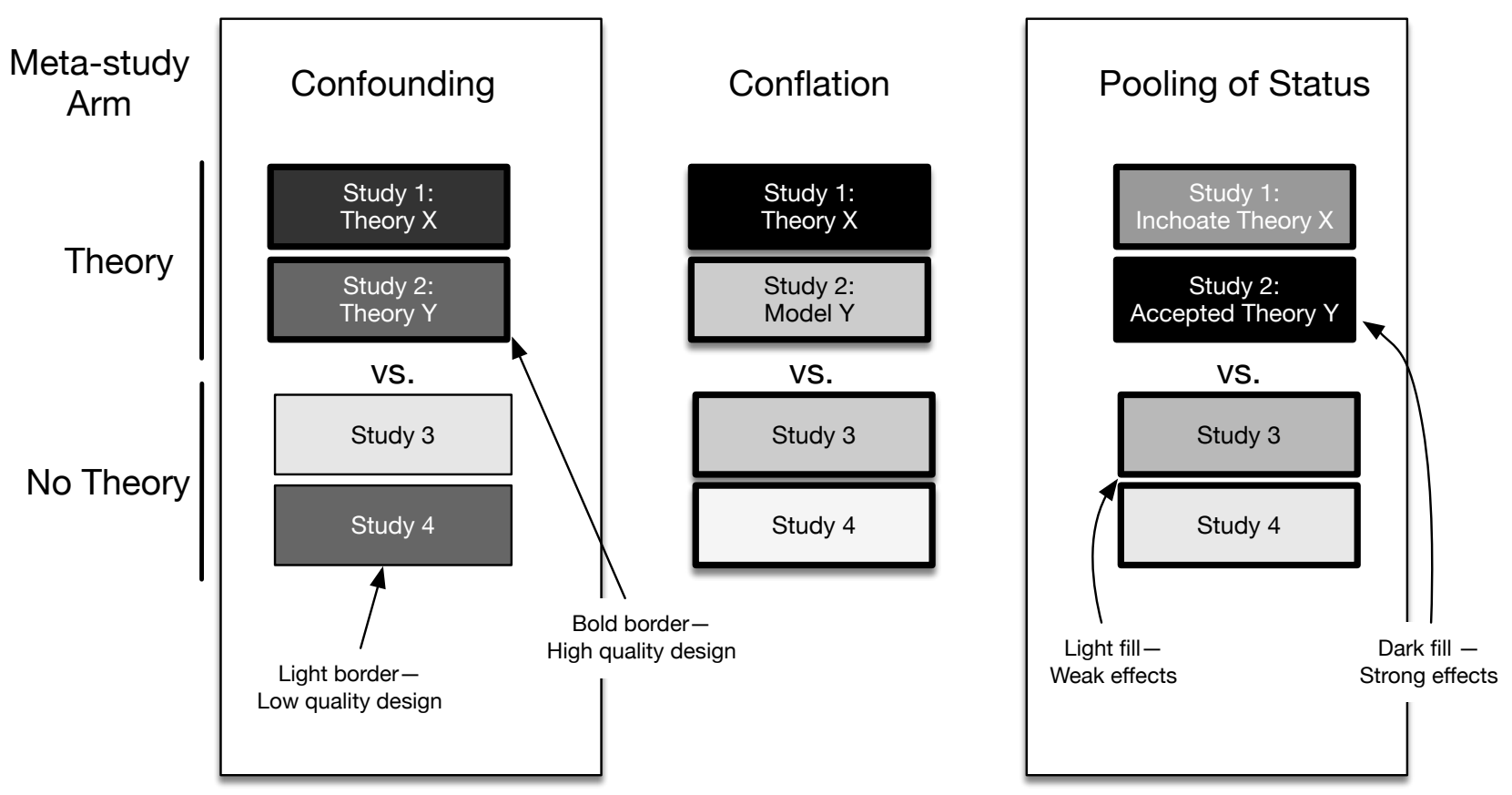

Figure 1. Diagrammatic representations of potential explanations for weak estimated effects of using theory-based interventions on the effectiveness for improved health-related outcomes. The diagram visualizes a comparison between a set of theory-based studies versus a set that did not use theory under three scenarios. Each box represents one study. Darker fill represents stronger estimated treatment effects. In the example confounding scenario, studies that use theory also have a higher quality experimental design. Studies with better designs have thick borders. The findings in Study 4 are overestimated. In the conflation scenario, studies that are based on models are treated as being theory-based, and so theories are pooled with other types of cognitive devices. In the pooling of status scenario, studies using proposed theories that are emerging or inchoate are pooled with accepted theories that have been accepted as correct because they have been successful and severely tested. Proposed theories may be incorrect or poorly formulated. In each hypothetical scenario, the overall effect in the theory arm may be attenuated by either confounding, conflation, or pooling.

\section{Distinguishing Between Invoking Theory and Using Theory}

Even among reviews reporting at least one supportive association between theory usage and outcomes, effect sizes have been small, inconsistent, only marginally significant, or questionable upon inspection of the interval estimates (Ammerman, Lindquist, Lohr, \& Hersey, 2002; Kim, 1997; Noar et al., 2007; Taylor, Conner, \& Lawton, 2012). This has left us in a situation where we are 
obliged to be cautious in predicting that HP theory, in its current form, will substantially raise the tide of intervention effectiveness. It is possible that a lack of large effect sizes could be a result of the attenuation caused by poor measurement of theory use and weakness in how experimental comparisons are constructed. However, in one reanalysis of prior meta-analyses where the manner in which theory was employed was added to the analysis, Prestwich et al. (2014) concluded the effects were at best weak.

In much of the literature, analyses of the benefits of theory often rely on markers of theory use that may be weakly valid for measuring the characteristics that proponents of theory use envision. Theory use is often dichotomously scored, based on whether or not a theory was invoked in a published report (Albada et al., 2009; Ammerman et al., 2002; Gardner, Wardle, Poston, \& Croker, 2011; Noar et al., 2007; Kim, 1997). There are reports of researchers admitting to only create a veneer of theory incorporation, just to please reviewers (Goodson, 2010). Thus, there may be no difference in intervention techniques among some projects invoking theory and those that do not (Michie, Jochelson, Markham, \& Bridle, 2009), yet those that only invoke theory get categorized as being theory-based in the early metanalyses. Many authors have recognized that research reports rarely include an adequate description of the nexus between theory and choices made in the engineering of the intervention (Albada et al., 2009; Gardner et al., 2011; Hagger \& Weed, 2019; Michie et al., 2009; Michie \& Prestwich, 2010). Several authors have presented means to ameliorate the instrumental measurement error with the use of structured instruments for measuring the use of theory (Michie \& Prestwich, 2010) and recommendations for the use of structured descriptions of the way in which theory influenced a given study (Bartholomew Eldredge et al., 2016; Peskin et al., 2017; Pot et al., 2018). Research questions, study design, intervention engineering, results interpretation, and conceptual integration can each be driven by theory. When research that presents theory only as a veneer is grouped with reports that are more richly anchored in theory, the cumulative evidence in the literature may be diluted from the mixing of studies that might meet the 
expectations of the proponents of theory use with those include the mention of theory as a token to proponents of theory-utilization.

\section{Conflation of Models and Theory}

Much of the theory-related vocabulary in HP is ambiguous (Bartholomew \& Mullen, 2011). There are several HP related expositions about theory that provide definitions of scientific theory (Glanz \& Bishop, 2010; Glanz, Rimer, \& Viswanath, 2015; Goodson, 2010; Nilsen, 2015). These varied treatments can be partially reconciled, but they poorly align with the divergent application of the terminology. For example, theory is sometimes used as an umbrella term for all conceptual devices, a term for a specific conceptual device type, a term used for causal explanations (Datta \& Petticrew, 2013; Hawe, 2015), or as the articulated rationale of an intervention (Davidoff, DixonWoods, Leviton, \& Michie, 2015). Frequently, the discussion of theory does not clearly distinguish which recommendations apply equally to conceptual devices titled model and those titled theory (Glanz \& Bishop, 2010). Fidelity to a taxonomy that differentiates these conceptual devices will aid evaluation and provide clarity to recommendations related to different types of conceptual devices. It will also help improve the assessment of the benefits of theory in HP. This conflation may help explain the current state of empirical evidence regarding the benefits of theory, as research anchored in models can be intermixed with well-formed strong theory. The latter should be expected to provide strong tools for the advancement of interventions, whereas the former's value will be highly contextdependent and little to gauge its potential for success without empirical calibration and evaluation in the context of current application.

For the remainder of this paper, classes of cognitive devices used for scientific representation will be differentiated. When referring to a specific type of cognitive device known as Theory, it will be denoted with a capital $\mathrm{T}$ to distinguish it from its looser use that includes all abstracted cognitive devices-including models (see Gray, 2017). 
Why are models and theory conflated in HP? To understand how this might have happened, first consider how theory is used in HP. As noted above, the most common link between intervention and study design with theory is via targeting of constructs found in a named theory. However, utilized constructs typically represent only a subset of a theory and are sourced from multiple theories (Albada et al., 2009; Noar et al., 2007; Michie et al., 2009; Prestwich et al., 2014). Notably, some studies without reference to any particular theory utilize constructs that are found in theories. In a review of print communication interventions, $96 \%$ of studies included concepts that authors traced to a referenced theory, although not always to the correct theory (Noar et al., 2007). Of the complement group of studies, $60 \%$ used a concept that qualified as a theoretical concept even though an associated theory was not described. In Noar's review, the mean number of concepts was four, which indicates that most studies use fewer constructs than in the referenced theories. In another review, only $9 \%$ of studies were found to have used all the constructs of a theory in an intervention (Prestwich et al., 2014). There is little indication that selected constructs are uniquely and solely deduced as the appropriate targets of intervention based on the content of a Theory.

Many forms of knowledge, including various forms of scientific representation, can function to provide lists of candidate constructs for intervention. Frameworks, models, theories, and lists from literature reviews can all function as construct inventories. For example, conceptual frameworks can be specifically developed to provide this function (Burkholder, Cox, Crawford, \& Hitchcock, 2019; Crosby, Kegler, \& DiClemente, 2009). Perhaps, because of the manner in which theory is used in HP the distinctions are often blurred among different types of conceptual devices (i.e., scientific representations such as frameworks, models, theories). The use of theory for providing construct inventories does not require the specific properties that distinguish each of these types of cognitive devices to be considered. The field now interchanges the term theory and models so frequently that the distinction has been functionally lost in many contexts; recommendations for the use of theory do not discriminate among the two. The prevalent way the term theory is used in HP is described by 
Glanz et al. (Glanz, Rimer, \& Viswanath, 2015). Citing Bandura, the function of theory is described by Glanz et al. as cataloging determinants of health behaviors (Bandura, 1986; Glanz, Rimer, \& Viswanath, 2015). It is recognized by Glanz et al. that this construction fundamentally differs from other sciences (Glanz, Rimer, \& Viswanath, 2015). Here is the problem; if the construction differs, the benefits may also differ. So, what are the differences?

For the exposition here, Theory is a hypothetical representation designed as a conceptual tool for structuring our thinking about phenomena (Boniolo, 2007). It is a device with specific characteristics that is used to represent scientific knowledge. The American Association for the Advancement of Science defines a scientific Theory as:

\section{A well-substantiated explanation of some aspect of the natural world, based on a}

\section{body of facts that have been repeatedly confirmed through observation and} experiment (American Association for the Advancement of Science, 2005).

Theories are neither conjecture, speculation, nor weakly supported. Thus, we should treat Theories as potentially accurate maps of the world (under a realist perspective). They should impart an understanding that is believed likely to be true (Achinstein, 1968; Harré, 2004). The portable knowledge of Theory can be leveraged as the basis for novel engineering approaches (Hacking, 1983). Theory of this sort could successfully direct HP intervention design.

At a different level, Theories are also described as abstract representations expressed as formal deductive systems that predict natural events (Thompson, 1989). They are large-scale systems of ideas about natural phenomena. They are also more general and elaborate units of knowledge than a typical hypothesis captures (Potochnik, Colombo, \& Wright, 2018). Theories provide general and formal means of organizing known empirical patterns, allow for the prediction of future empirical observations, and give meaning to those patterns (Boniolo, 2007). Theory is also considered a source of solutions to problems, in the form of explanations for the various patterns associated with a specified type of phenomenon (Harré, 2004; Popper, 1994). 
Theory outlines the constituents, their interactions, and mechanisms of the processes that result in the patterns. This is more than a collection of constructs connected by a limited set of qualitative associations. Theory provides explanations for observable phenomena, provides the structure that grants predictions about those phenomena, and delineates the scope of applicability. General features of scientific Theories include: 1) a set of interrelated propositions, concepts, and definitions, 2) a specific domain of applicability, 3) a description of relationships between components, 4) mechanistic explanations for the relationships, and, consequently, 5) predictions about the behavior of the system. Although this list is more inclusive than reported by others in the social sciences, it is consistent with their intent (Imenda, 2014; Wacker, 1998). Definitions developed specifically for health behaviors research focus on features 3 and 5 (Davis, Campbell, Hildon, Hobbs, \& Michie, 2015), which are also consistent with other forms of scientific representation. It should be acknowledged that not all conceptual devices identified as Theory clearly contain all five attributes or other diagnostic criteria described below.

The features of Theory are not settled. There has been substantial philosophical dialogue about what should constitute a Theory (Winther, 2018; Lambert \& Brittan, 1992). This may, in part, reflect the flexibility that scientists provide in the identification of Theory. However, the benefits attributed to Theory across the sciences are based on well-formed hypothetico-deductive Theories, which meet the criteria presented here. This point should be considered when developing recommendations and adopting working definitions of theory in HP.

Falsifiability is the most distinguishing diagnostic feature of scientific Theory. Theory should, in principle, provide clear opportunity to identify distinct predictions about future empirical observations that would trigger the demotion of the Theory if borne out (McMullin, 1976). Naïve methodological falsification is achieved if investigation of the types of features and patterns used to generate and justify the Theory later present patterns leading to the Theory's refutation. Sophisticated methodological falsification relies on the capacity of the Theory to deductively predict novel facts 
about nature. These novel patterns are the knowledge created by Theory-Theories are more than devices for capturing accumulated knowledge. Deductively discovered knowledge is a chief benefit of Theory.

Theories are not amenable to universal verification, so falsification tests are our strongest tools in solidifying our commitment to a Theory. Falsifiability is so pivotal that it has been considered a demarcation between science and pseudoscience (Mayo, 2019; Popper, 1994; Staley, 2014). Taking an alternative view that science operates instead on gauging the verisimilitude of a Theory can be compatible with accepting that some explanations can be wrong and in need of discarding (Gardner et al., 2011; Michie et al., 2009)See (Brink, 2017), and, Popper 1994, for a discussion of verisimilitude). Theory is more than a prediction device. Explanation paves the way for understanding how our world operates. Public health infrequently emphasizes Theory's falsifiability (or verisimilitude) as a critical feature (Noar \& Zimmerman, 2005; Michie, West, Campbell, Brown, \& Gainforth, 2014; cf. Goodson, 2010). Rarely are specific novel predictions of HP conceptual devices identified, and even more rarely are they severely tested (see Chalmers, 2013; Chalmers, 2010; Mayo, 1991; Popper, 2014). As described below, this may be a consequence of an ambiguous conception of theory in HP and the sparsity of cognitive devices applicable to HP that produce novel deductive predictions.

\section{Theory Form: How Do Philosophers View Theory?}

Although scientists need not adopt philosophers' perspectives (Murray, 2001), there is benefit in reviewing their contributions. They have built a substantial literature focused on describing the structure and properties of scientific Theories. Different philosophical perspectives on the idealized form of theory include the: syntactic, semantic, and pragmatic views of Theory. The interested reader can refer to the supplemental material for a description of these views. The reader will find that a cognitive device that simply inventories determinants of a health behavior is inconsistent with the 
structures that philosophers have painstakingly mapped out as a means to capture the essence of scientific Theory.

It is critical for health behavior researchers to evaluate whether cognitive devices used in HP conform to the structure presented under these views. It is clear that Theory, under the syntactic or semantic view, is not a collection of antecedents of a health behavior, which is sufficient to be classified as a Theory in HP (Goodson, 2010). However, if the desired benefits of Theory are a consequence of the properties associated with the desiderata presented here (Table 1), we should consider labeling cognitive devices that are just inventories of determinants as Theory to be a classification error. Theories are much more than that.

Philosophical analysis of Theory is grounded in the details of how science is practiced. On the other hand, scientists are more interested in building knowledge than delving into the abstract structural analysis of scientific representation. Nonetheless, the current state of HP, and other behavioral sciences, makes it valuable to consider the abstract structure of Theories. For example, the philosophical views remind us that Theory should self-describe where and why a Theory is applicable. For instance, formalized inclusion of the demarcated limits of the Theory's domain of application is a key feature of Theory identified by philosophers (Staley, 2014). Explicit description of the class of phenomena to which a cognitive device is applicable (i.e., domain of applicability) is often overlooked or weakly developed, in cognitive devices branded as Theory in HP. Under the semantic perspective, the absence of crisp information to this point would disqualify a cognitive device as Theory. Identification of an appropriate cognitive device for application to a particular HP intervention is a challenge for the field because HP theories do not adequately describe their domain of applicability as would be expected in well-formed theories.

\section{Features of Theory: How Do Scientists View Theory?}

What should we look for in HP Theories? The presentation of the diagnostic features of Theory 
includes only some of the characteristics associated with well-formed Theory. A comprehensive suite of characteristics is provided here by combining typical exemplar descriptions that are outlined in Table 1. This table illustrates substantial differences in the conceptualization and practical application of Theory usage in HP as compared to other sciences. There is overlap, but the overlap is not on the diagnostic features. As in the HP literature, the most common descriptions of Theory indicate that it is explanatory and predictive. Explanation requires knowledge of the causal mechanism. Prediction can come from models with no links to causal mechanisms. Working definitions and treatment of Theory in HP does not consistently include overlap with the characterization of Theory presented in this paper, especially among those characteristics that are unique to Theory.

To illustrate the differences, a synthesis of these characterizations is sketched here (Table 1). Theory is systematic, such that it describes consistent relationships among all of the components. It is complete where Theory specifies the effect across the components' ranges (Meehl, 1990). Theory is discrete in that it is built out of context-independent elements, where features of Theory structure (not content) are devoid of cultural influence, including traditions and values. Ideally, well-formed Theory can be decoded in the same way by all persons, regardless of their cultural lens. Theory is predictive in that its consequences can be verified by empirical observation (Flyvbjerg, 2001). Natural scientists also describe Theory as being adequately described to eliminate ambiguity. Its propositions should be clear. Falsifiability is often omitted from characteristic lists. It is often treated implicitly as the overarching diagnostic feature of science and its Theories. In this paper, falsifiability is treated as a hallmark of scientific Theory.

HP researchers also included explanation and prediction as features of theory (Table 1). However, the ability of a Theory to explain and predict varied phenomena is not emphasized. This is the unificatory property of the explanations found in well-formed Theories (Kitcher, 1997). HP researchers do list testability as a feature of Theory (Table 1). However, few cognitive devices in HP have been put to tests that could have falsified them (Michie, West, Campbell, Brown, \& Gainforth, 
2014). This may be an indicator that cognitive devices that HP has labeled as Theory do not produce deductively derived risky novel predictions expected of well-formed Theory. If a cognitive device is model, we do not need to test it. They are all wrong. This is a good point to recognize that the behavioral sciences have broadly suffered from applying loose criteria to what can be labeled a Theory, including cognitive devices that do not deductively produce new predictions (Gigerenzer, 2011).

\section{- Table 1 About Here -}

Several features that are particularly relevant to the consideration of leading HP cognitive devices were highlighted by Achinstein (1968)(Table 1). The first is that Theory is not directly derivable from another Theory without at least non-trivial integration of additional premises; Theory is nonderivative. Theory is elemental; it is distinct from other Theories, non-severable, and not an amalgamation of their components. Theory is something that can be believed to be true and not known to be false. Being a useful instrument for control and prediction is not enough. Instead, we treat it as if it possesses truth value. Consequently, Theories are neither modular nor interchangeable alternatives. Contrast that view with an important compendium of behavior change theories that provides a large set of alternative options for cognitive devices to be used in HP and explicates how the constructs in the cognitive device are derived from what are called contributing theories (Michie, West, Campbell, Brown, \& Gainforth, 2014). In other sciences, one Theory may rely on other Theories to provide its axioms. This is very different than extracting components from another conceptual device to populate the constructs and links within a new cognitive device.

There are several features often left out of descriptions of Theory, but may have been omitted because they are implicit. For example, Theory should be universal (Table 1); the Theory should apply in all places, times, and contexts. As mentioned above, another common omission is that Theory has a specific domain of applicability (Staley, 2014). This is particularly relevant in the study of complex systems. When does a Theory apply? HP professionals should be clear as to whether or 
not a Theory is applicable to a particular health behavior by simple inspection of the Theory. A wellformed Theory will ably self-describe the delineation of its domain.

Contemporary views in HP include generalizability in the description of the characteristics of Theory (or are included as a dimension of Theory quality; Table 1). However, this characteristic is difficult to reconcile as it implies that the Theory should be applicable across populations, behaviors, and settings of an unspecified breadth in the context of the current state of the field. Where Theory includes its domain of application, and it is universal, the concept of generalizability of a Theory is subordinated.

Finally, Theory should include a set of propositions, where the propositions include central, distinctive, and integrated assumptions. The central propositions are the minimally sufficient set required for the Theory to function. Theory is a set of consequences of some specified axioms. The integrated assumptions may be consequences of other Theories, but a Theory's propositions distinguish it from all other Theories.

Why walk through all these features of Theory? To highlight the point that Theory is much richer than an inventory of antecedents, which is currently accepted as an operational definition of theory in HP (Glanz, 2005; Goodson, 2010, p. 151). Variance in the conceptualization of theory is also recognized within the HP literature (Glanz, Rimer, \& Viswanath, 2015; Goodson, 2010). Where Theory as a distinct type of cognitive device is defined, its features include description, explanation, and prediction (Glanz, Rimer, \& Viswanath, 2015; Goodson, 2010). However, "sets of tested empirical generalizations," "theoretical orientations or perspectives," and "various types of ideas, speculations, hypotheses, models, criticisms, conceptual frameworks, or any propositions interconnected with words (and even scholars' personal beliefs) are sometimes called theory" (Goodson, 2010, p.7). HP doesn't consider its theories to be systematic; use of a particular theory can cause a "blinding effect," where a researcher fails to consider important processes that are absent from the chosen cognitive device (Goodson, 2010, p. 86). Well-formed scientific Theories are less 
vulnerable to this type of effect because they are systematic and complete; they contain what they need.

In terms of benefits, cognitive devices titled as models are often treated as equivalent to those titled Theory in HP (Lucas \& Lloyd, 2005). One response to this state is Goodson's view of theory, where theory is pluralistic, instrumental, and intimately connected to the process of explanation. Here, cognitive devices resulting from the process of answering questions of causal explanation are theories. Goodson weaves a pragmatic approach by considering context and meaning with the development of explanations (Goodson, 2010). The power of theory is then tied to the power of explanation. However, the resultant cognitive device may not possess the features of Theory presented above (Table 1). Again, not all forms of explanations provide the same benefits. A chief benefit of Theory is the novel knowledge that is deductively derived. Salient examples of this are the black hole imagery predicted by the Theory of Relativity (Event Horizon Telescope Collaboration et al., 2019). Another example is the Theory of Plate Tectonics' ability to explain and predict global patterns of biogeography, in addition to unifying disparate geological patterns (Raven \& Axelrod, 1974; Briggs, 1987). If the intent is to consider any explanation a Theory, the proposed benefits should match this looser construction. Estimation of effects of Theory will be clouded when they are mixed with other types of cognitive devices.

\section{An Example from Health Promotion}

The Theory of Planned Behavior (TPB) has features that map to Theory, but many other features are absent or deficient (Table 1). This does not discount TPB's contribution to HP (Montano \& Kasprzyk, 2015). The intent of TPB was to provide an explanation for most behaviors of interest to social psychologists (Ajzen, 2011). The broad edges of this putative domain of application are not entirely explicit; TPB does not self-describe when it is applicable (without creating a tautology). This is common among conceptual devices for health behaviors and often results in broad application 
beyond a conceptual device’s original development contexts (Hagger \& Weed, 2019).

TPB's structure has changed in recognition of limitations to behavioral control. This is why the perception of control construct was appended to the Theory of Reasoned Action to arrive at the TPB (Ajzen, 2011). Ajzen (2011) also recognized that actual control should be considered part of the causal system and that the perceptions construct could be used as a proxy. The fuzziness regarding which (or when a) control construct should operate reduces the explicitness of the theory. This is also an admission that the conceptual device is not systematic, because it is implied that the relationship between actual control and perceptions varies in ways that are not described by the theory. The simplest indicator that TPB is not a well-formed theory is that it is not elemental, because the Theory of Reasoned Action is a subdivision of TPB.

TPB holds behavioral intentions as the proximal driver of behaviors (Ajzen, 2011). Implicit in the TPB is that cognition drives an intention mediated process leading to goal-oriented behavior (Ajzen, 2011). This leaves out what we know about the influence of unconscious processes on many behaviors (Kahneman, 2011; Chaiken \& Trope, 1999). Although dual-systems influencing behavior may be mediated by the same constructs (Ajzen, 2011), this is not a feature of TPB. Substance use researchers are particularly attuned to the role of non-cognitive behavioral influences (Koob \& Volkow, 2016; Norman \& Conner, 2006; Norman, 2011; Pulido, Brown, Cummins, Paulus, \& Tapert, 2010), which can profoundly conflict with distal behavioral intentions. Developmental researchers are also forced to recognize the keystone role of self-regulation (Miller, Lo, Bauer, \& Fredericks, 2020), which can be requisite for planned behavior to manifest into action. Further, affective processes are known to influence behavior (Kiviniemi et al., 2018; Lerner, Li, Valdesolo, \& Kassam, 2015; Lerner \& Shonk, 2010; Mendl \& Paul, 2020). Most health behaviors of concern are likely to be influenced in part by processes not addressed in the TPB, even those that are dominated by deliberate planning. As with many health behavior conceptual devices, the structure of the TPB 
appears to only capture one branch of the complex network of behavioral influences in which it is embedded. Well-formed theories address the whole of interrelated phenomena.

Critically, Theory should describe and explain to which phenomena it is applicable, and that is not adequately developed for consistent application of conceptual devices in HP. As a Theory, it is certainly not unificatory, as it is a conceptual device that is limited to those behaviors for which it ends up describing, without linking otherwise seemingly unrelated phenomena. Even where behavior appears to be overwhelmingly driven by TPB's cognitions and behavioral intention and control constructs, the TPB is not considered by the field as likely to be true, systematic, or certain to outcompete all other conceptual devices for a clearly defined class of behaviors. Thus, in HP the use of TPB is treated as discretionary. If it were considered as likely correct or superior, its use would be expected, rather than an optional alternative.

TPB includes a list of external factors, such as demographics, which do not have clearly defined relationship structures with other features of the Theory; this is another indication that TPB is not systematic. Worse, these external factors have been found to operate outside the pathways described by the TPB (Sniehotta, Presseau, \& Araújo-Soares, 2014). Further, none of the relationships are quantified for any part of their range (Meehl, 1990). As with most health behavior theory, it is unclear to what degree TPB provides unique quantitative, or even qualitative, prediction or control. There are some causal paths in this model, yet an interventionist would not know which is the most crucial, effective, or efficient to intervene upon, because the strength of their effect is not specified (Rothman, 2004). There are no risky novel predictions that emerge from TPB, which has resulted in it being considered unfalsifiable (Greve, 2001; Ogden, 2003; Smedslund, 2000). This reflects its semi-amorphous nature and application. Its falsifiability has been claimed under specific formulations (Trafimow, 2015). However, under this view, it has already been falsified (Trafimow, 2015). TPB does not provide a systematic, delineated, and fully explicit account of a range of specified phenomena. 
Despite calls for its abandonment (Sniehotta et al., 2014), TPB can provide service to HP, but it will not provide the benefits of a well-formed Theory. Deficiencies of conceptual devices treated as Theory may help explain the generalized discounting of benefits for all theory in HP. A common deficiency is an inadequate description of the conceptual device's domain of application. TPB does not work for many health behaviors to which it has been applied (Sniehotta et al., 2014). Is that because TPB is not true or because TPB has been applied to health behaviors beyond its domain of applicability? Practitioners feel unguided as to when a particular conceptual device is to be used, but a well-formed Theory should answer that question. Researchers have not been discriminating between theory application that was within the domain of applicability and when it is beyond the domain when evaluating the efficacy of interventions based on theory in the literature. Why should misapplied Theory be expected to improve health outcomes? Why should any of a multitude of competing proposed Theories be expected to equally benefit researchers and practitioners? It may be the lack of discrimination on these characteristics is washing out the results of meta-analyses on the use of Theory. However, the biggest challenge for Theory faced by HP may be exemplified by the TPB. TPB should not be expected to function as a Theory when it has few characteristics of wellformed Theory and is better categorized as a model.

\section{Misclassification of Theory Status: All Theories Are Not Equally Valuable}

Another consideration is the paucity of evaluation and discussion of the specific theory used in studies. A functional definition of Theory that allows any cognitive device to suffice means suboptimal cognitive devices will dilute the effects of stronger cognitive devices (Figure 1), such as a severely tested Theory, when their effects are pooled (see Chalmers, 2013; Chalmers, 2010; Mayo, 1991; Popper, 2014 for discussions about types of severe tests). This is underappreciated. There is a recognition that some Theories may be inappropriate for the contexts in which they were applied, but the verisimilitude of the candidate Theories is not adequately considered (Gardner et al., 2011; Michie et al., 2009 see Brink, 2017 and Popper, 1994 for a discussion of verisimilitude). More 
plainly, if studies using Theories that are poor or are not applicable are categorized as being Theorybased then we may be obscuring the effects of using well-formed Theory applied within its domain of application. Demarking whether the Theory that is applicable to the problem at hand is used, rather than just any theory, will reduce cloudiness in the evidence for the benefit of theory. This can be accomplished within a broader effort to deliberately structure the way cognitive devices are used, analyzed, and categorized.

For a particular domain of application, if there is an available Theory that has become engrained in the field, because it has been substantiated and severely tested, that is the Theory that should be selected for use. Incipient, emerging, or inchoate Theory may be available and suitable in some research contexts. A Theory that has not yet been accepted as correct should rarely be adopted for public health practice when an accepted Theory is available. In no instance should the use of less established Theories be treated equivalently to the use of a Theory that has reached the status of been widely regarded as (at least approximately) correct. The same can be said about using a tarnished Theory, which had been considered correct but critical anomalies put its verisimilitude in jeopardy.

When studies evaluate the benefits of using Theory the most important features that can be recorded is if the health behavior is consistent with the Theory's domain of application and the status of the Theory (e.g., emerging, tarnished, accepted). Currently, researchers in HP rarely distinguish among the evidentiary status of different theories, and implicitly classify all as if they were accepted Theories. The estimated benefits of using Theory will likely be diluted in evaluations that mix Theories of varied evidentiary status or if inapplicable Theory is used (Figure 1).

\section{Discussion}

Many of the conceptual devices used in HP operate more as models or conceptual frameworks than Theory. Different types of conceptual devices should not be expected to achieve the same success. Under the interdisciplinary view of Theory presented here, established Theories are treated as 
approximately true, and models are recognized as being wrong. Those conceptual devices that are strong in the features of Theories presented here should be expected to provide stronger benefits to the development of interventions. The targeting of mediators in an accepted Theory that applies to a particular health behavior should not be considered speculative. These considerations are not currently reflected in how Theory is used and evaluated in HP.

Under the view presented here, the field would treat features of an accepted Theory as established knowledge. Practitioners conflating Theory and models may become distrustful of claims that Theory can provide service to the engineering of interventions. The same can be said about treating an incompletely formed or incipient Theory with one considered as correct (or one with strong verisimilitude); recommendations for the use of Theory as a basis for public health interventions should include the distinction between accepted and proposed Theory (Cummins, 2020). Given that current working descriptions of Theory in HP do not incorporate many of the features presented here, it is difficult to rely on the HP literature itself to identify which cognitive devices possess the characteristics of well-formed Theory. HP may not have recognized the gap because there is a scarcity of well-formed strong Theory that can be used to create significant contrasts against conceptual devices of other types.

Several challenges to the empirical evaluation of the benefit of Theory in HP have been presented in this paper. The confounding (Figure 1) can be addressed with improved study design. Categorical blurring of conceptual devices and status pooling (Figure 1) can be attributed to the loose conceptual and lexical treatment of theory that diverges from the way that Theory is constructed in other scientific disciplines. With corresponding conceptual development, these can be addressed with instrumentation that is sensitive to different types of conceptual devices (e.g., models, Theories) and Theory status (e.g., tarnished, proposed, accepted).

These challenges and the broader debate (Hagger \& Weed, 2019) over the importance of the use of Theory in HP misses a fundamental consideration. Does HP have Theories? If it does, which 
of its conceptual devices have the characteristics of Theory and are considered by the field to be at least approximately correct? Answers to those questions should be at the heart of every evaluation of the benefit of Theory. Every meta-analysis should evaluate whether or not the accepted Theory for the particular domain was applied. Because of its dominant application, we used the TPB as an exemplar. There is no consensus that TPB is the correct Theory for any restricted class of phenomena. TPB's features are deficient in regards to the desiderata of Theory presented here (Table 1). Future empirical evaluation of Theory will be enhanced by gauging the type and status of each empirical device being employed in the HP researcher, even if different diagnostic characteristics of Theory other than what was presented here are used.

Deficiencies should be expected of the majority of conceptual devices in HP, as evidenced by three observations. First, capricious and subjective selection of conceptual devices (and their internal components) is the current practice rather than consistent deference to a whole Theory that is considered correct for the specific domain of application. Second, current efforts to define and maintain a consistent taxonomy of conceptual devices have not successfully resulted in consistent discrimination between models and Theories. Third, the related vocabulary regarding conceptual devices in HP has become ambiguous and amorphous (Bartholomew \& Mullen, 2011; Datta \& Petticrew, 2013; Hawe, 2015). Finally, exclusive novel predictions that are deductively developed are not emphasized, much less listed, in HP literature used to organize, describe, and catalog the field's theoretical landscape.

Flyvbjerg (2001) makes a strong argument that Theory, as construed in the natural sciences, may not be attainable in the social sciences (Flyvbjerg, 2001). Glanz et al. $(2015$, p. 26) has also acknowledged the absence of well-formed Theory in health promotion. However, HP has not wrestled with the implications of this admission, whereas Flyvbjerg (Flyvbjerg, 2001) concluded that it might be counterproductive to even use the word theory in social sciences. Conceptual devices that only attain some of the features of well-formed Theory should not be expected to provide the benefits 
of Theory. Consider models. They are fictive representations that are wrong (Boniolo, 2007; Harré, 2004). The scientist wielding a particular model has used scientific judgment to pick the balance between precision, generalizability, and realism to fit the specific needs of her application (Levins, 1966). Contrast that that with the application of a Theory, which is considered at least potentially approximately correct and thus consistently employed. Were HP to consistently discriminate between models and Theory conflation would decrease and the need for the appraisal of the evidentiary status of each of its Theories would become starkly evident.

Theory is the most powerful form of scientific representation. There are disciplines in the physical and life sciences that have not been able to attain Theories (Cummins, 2020). Lessons from these disciplines can be used to form guidance on how the field can progress with strong conceptual foundations in the absence of HP Theory. For example, the use of bounding principles (Cummins, 2020), phenomenological modeling (Cummins, 2020; Boniolo, 2007), and paratheoretical framing (Cummins, 2020) can provide attainable theoretical service for the field. Consideration of the potential benefits of these alternative means for framing research, developing interventions, and creating scientific representations will be most robust in fields that recognize that well-formed accepted Theory may be elusive. Before evaluating and then debating the effects of using theory in HP, we should first ask if we even have Theories to apply and evaluate. Were Theories to be identified and their characteristics align with those suggested in Table 1, the conflation and pooling challenges presented in this paper can be easily ameliorated.

The current reliance on indirect evidence to support the use of Theory, combined with the indeterminate usage of theory, results in several deficiencies in the evidence base available for evaluating Theory's benefit. Yet, the widely recognized power of theory to provide structures for research and engineering success across the science has not, and should not, be discounted by health behavior researchers. 
Theory in Health Promotion

\section{References}

Achinstein, P. (1968). Concepts of Science: A Philosophical Analysis. Baltimore: The Johns Hopkins Press.

Ajzen, I. (2011). The theory of planned behavior. In P. A. van Lange, A. W. Kruglanski, \& E. T. Higgins (Eds.), Handbook of theories of social psychology. New York: Lawrence Erlbaum Associates.

Albada, A., Ausems, M., Bensing, J. M., \& van Dulmen, S. (2009). Tailored information about cancer risk and screening: a systematic review. Patient Education and Counseling, 77(2), 155171.

American Association for the Advancement of Science. (2005). Evolution on the Front Line: Q \& A on Evolution and Intelligent Design. Retrieved October 29, 2005, https://www.aaas.org/news/press_room/evolution/qanda.shtml.

Ammerman, A. S., Lindquist, C. H., Lohr, K. N., \& Hersey, J. (2002). The efficacy of behavioral interventions to modify dietary fat and fruit and vegetable intake: a review of the evidence. Preventive Medicine, 35(1), 25-41.

Bandura, A. (1986). Social Foundations of Thought and Action: a Social Cognitive Theory. Englewood Cliffs, NJ: Prentice-Hall.

Bartholomew Eldredge, L. K., Markham, C. M., Ruiter, R. A. C., Fernández, M. E., Kok, G., \& Parcel, G. S. (2016). Planning health promotion programs: an intervention mapping approach. John Wiley \& Sons.

Bartholomew, L. K., \& Mullen, P. D. (2011). Five roles for using theory and evidence in the design and testing of behavior change interventions. Journal of Public Health Dentistry, 71, S20-S33.

Boniolo, G. (2007). On Scientific Representations: From Kant to a New Philosophy of Science. Springer.

Briggs, J. C. (1987). Biogeography and Plate Tectonics. Elsevier.

Brink, C. (2017). Verisimilitude. In Newton-Smith (Ed.), A Companion to the Philosophy of Science. New York: Blackwell Publishing Ltd.

Burkholder, G. J., Cox, K. A., Crawford, L. M., \& Hitchcock, J. H. (2019). Research Design and Methods. Thousand Oaks, CA: SAGE Publications.

Cadigan, J. M., Haeny, A. M., Martens, M. P., Weaver, C. C., Takamatsu, S. K., \& Arterberry, B. J. (2015). Personalized drinking feedback: a meta-analysis of in-person versus computer-delivered interventions. Journal of Consulting and Clinical Psychology, 83(2), 430.

Carey, K. B., Scott-Sheldon, L. A., Carey, M. P., \& DeMartini, K. S. (2007). Individual-level interventions to reduce college student drinking: a meta-analytic review. Addictive Behavior, 32(11), 2469-2494.

Chaiken, S., \& Trope, Y. (1999). Dual-process Theories in Social Psychology. New York: Guilford Press.

Chalmers, A. (2010). The life of theory in the new experimentalism. In D. G. Mayo \& A. Spanos (Eds.), Error and Inference: Recent Exchanges on Experimental Reasoning, Reliablity, and the Objectivity and Rationality of Science (pp. 58-72). New York: Cambridge University Press.

Chalmers, A. F. (2013). What Is This Thing Called Science?: Forth Edition. Hackett Publishing.

Cummins, K. (2020, August 22). Reforming the Use of Theory in Health Promotion: Lessons from Ecology. Retrieved from osf.io/4vfph

Crosby, R. A., Kegler, M. C., \& DiClemente, R. J. (2009). Theory in health promotion practice and research. In Emerging Theories in Health Promotion Practice and Research (pp. 3-18). San Francisco: Jossey-Bass.

Datta, J., \& Petticrew, M. (2013). Challenges to evaluating complex interventions: a content analysis of published papers. BMC Public Health, 13, 568. 
Davidoff, F., Dixon-Woods, M., Leviton, L., \& Michie, S. (2015). Demystifying theory and its use in improvement. BMJ quality \& safety, 24(3), 228-238.

Davis, R., Campbell, R., Hildon, Z., Hobbs, L., \& Michie, S. (2015). Theories of behaviour and behaviour change across the social and behavioural sciences: a scoping review. Health Psychology Review, 9(3), 323-344.

DiClemente, R. J., Crosby, R. A., \& Kegler, M. C. (2009). Emerging Theories in Health Promotion Practice and Research. John Wiley \& Sons.

Event Horizon Telescope Collaboration, Akiyama, K., Alberdi, A., Alef, W., Asada, K., Azulay, R. et al. (2019). First M87 event horizon telescope results. I. the shadow of the supermassive black hole. The Astrophysical Journal, 875(1), L1.

Flyvbjerg, B. (2001). Making social science matter: Why social inquiry fails and how it can succeed again. Cambridge, UK: Cambridge University Press.

Gardner, B., Wardle, J., Poston, L., \& Croker, H. (2011). Changing diet and physical activity to reduce gestational weight gain: a meta-analysis. Obesity Reviews, 12(7), e602-e620.

Gigerenzer, G. (2011). Surrogates for theory. APS observer, 22(2).

Glanz, K., \& Bishop, D. B. (2010). The role of behavioral science theory in development and implementation of public health interventions. Annual Review of Public Health, 31, 399-418.

Glanz, K., Rimer, B. K., \& Viswanath, K. (2015). Health Behavior: Theory, Research, and Practice (Fifth Edition ed.). San Fransisco: Jossey-Bass.

Glanz, K. (2005). Theory at a Glance: a Guide for Health Promotion Practice. Second Edition. (2nd ed. ed.). Bethesda: U.S. Dept. of Health and Human Services, National Cancer Institute.

Goodson, P. (2010). Theory in Health Promotion Research and Practice: Thinking Outside the Box. Sudbury, Mass: Jones and Bartlett.

Gray, K. (2017). How to map theory: reliable methods are fruitless without rigorous theory. Perspectives on Psychological Science, 12(5), 731-741.

Greve, W. (2001). Traps and gaps in action explanation: Theoretical problems of a psychology of human action. Psychological Review, 108(2), 435.

Hacking, I. (1983). Representing and Intervening. Cambridge University Press.

Hagger, M. S., \& Weed, M. (2019). DEBATE: Do interventions based on behavioral theory work in the real world. Int J Behav Nutr Phys Act, 16(1), 36.

Hale, J., Hastings, J., West, R., Lefevre, C. E., Direito, A., Bohlen, L. C. et al. (2020). An ontologybased modelling system (OBMS) for representing behaviour change theories applied to 76 theories. Wellcome Open Res, 5, 177.

Haller, M., Norman, S. B., Cummins, K., Trim, R. S., Xu, X., Cui, R. et al. (2016). Integrated cognitive behavioral therapy versus cognitive processing therapy for adults with depression, substance use disorder, and trauma. Journal of Substance Abuse Treatment, 62, 38-48.

Harré, R. (2004). Modeling: Gateway to the Unknown: a Work (1). New York: Elsevier.

Hawe, P. (2015). Lessons from complex interventions to improve health. Annual Review of Public Health, 36, 307-323.

Imenda, S. (2014). Is there a conceptual difference between theoretical and conceptual frameworks. Journal of Social Sciences, 38(2), 185-195.

Kahneman, D. (2011). Thinking, Fast and Slow. New York: Farrar, Straus and Giroux.

Kim, N. (1997).

Kitcher, P. (1997). Explanatory unification. Philosophy of Science.

Kiviniemi, M. T., Ellis, E. M., Hall, M. G., Moss, J. L., Lillie, S. E., Brewer, N. T. et al. (2018). Mediation, moderation, and context: Understanding complex relations among cognition, affect, and health behaviour. Psychology and Health, 33(1), 98-116.

Koob, G. F., \& Volkow, N. D. (2016). Neurobiology of addiction: a neurocircuitry analysis. The Lancet Psychiatry, 3(8), 760-773. 
Krieger, N., \& Zierler, S. (1996). What explains the public's health?: a call for epidemiologic theory. Epidemiology, 107-109.

Lambert, K., \& Brittan, G. G. (1992). An Introduction to the Philosophy of Science: Forth Edition. Atascadero, CA: Ridgeview Publishing Company.

Lerner, J. S., Li, Y., Valdesolo, P., \& Kassam, K. S. (2015). Emotion and decision making. Annual review of psychology, 66, 799-823.

Lerner, J. S., \& Shonk, K. (2010). How anger poisons decision making. Harv Bus Rev, 88(9), 26.

Levins, R. (1966). The strategy of model building in population biology. American Scientist, 54(4), 421-431.

Lewin, K. (1951). Field Theory in Social Science. New York: Harper.

Lippke, S., \& Ziegelmann, J. P. (2008). Theory-based health behavior change: developing, testing, and applying theories for evidence-based interventions. Applied Psychology, 57(4), 698-716.

Lock, M., Post, D., Dollman, J., \& Parfitt, G. (2020). Efficacy of theory-informed workplace physical activity interventions: a systematic literature review with meta-analyses. Health Psychol Rev, 125.

Lucas, K., \& Lloyd, B. (2005). Health Promotion. Thousand Oaks, CA: SAGE.

Mayo, D. G. (1991). Novel evidence and severe tests. Philosophy of Science, 58(4), 523-552.

Mayo, D. G. (2019). Statistical Inference as Severe Testing. Cambridge University Press, Cambridge.

McCain, K. W. (2015). Nothing as practical as a good theory: does Lewin's Maxim still have salience in the applied social sciences. Proceedings of the 78th ASIS\&T Annual Meeting: Information Science with Impact: Research in and for the Community, 52(1), 1-4.

McMullin, E. (1976). The fertility of theory and the unit for appraisal in science. In Essays in Memory of Imre Lakatos (pp. 395-432). New York: Springer.

Meehl, P. E. (1990). Appraising and amending theories: the strategy of lakatosian defense and two principles that warrant it. Psychological Inquiry, 1(2), 108-141.

Meier, P. S., Barrowclough, C., \& Donmall, M. C. (2005). The role of the therapeutic alliance in the treatment of substance misuse: a critical review of the literature. Addiction, 100(3), 304-316.

Mendl, M., \& Paul, E. S. (2020). Animal affect and decision-making. Neurosci Biobehav Rev, 112, 144-163.

Michie, S. F., West, R., Campbell, R., Brown, J., \& Gainforth, H. (2014). ABC of behaviour change theories. Silverback Publishing.

Michie, S., Jochelson, K., Markham, W. A., \& Bridle, C. (2009). Low income groups and behaviour change interventions: a review of intervention content, effectiveness and theoretical frameworks. Journal of Epidemiology \& Community Health, 63, 610-622.

Michie, S., Johnston, M., Francis, J., Hardeman, W., \& Eccles, M. (2008). From theory to intervention: mapping theoretically derived behavioural determinants to behaviour change techniques. Applied Psychology, 57(4), 660-680.

Michie, S., \& Prestwich, A. (2010). Are interventions theory-based? development of a theory coding scheme. Health Psychology, 29(1), 1.

Miller, A. L., Lo, S. L., Bauer, K. W., \& Fredericks, E. M. (2020). Developmentally informed behaviour change techniques to enhance self-regulation in a health promotion context: a conceptual review. Health Psychology Review, 14(1), 116-131.

Montano, D. E., \& Kasprzyk, D. (2015). Theory of reasoned action, theory of planned behavior, and the integrated behavioral model. In K. Glanz, B. K. Rimer, \& K. Viswanath (Eds.), Health Behavior: Theory, Research and Practice (pp. 95-120). San Fransisco: Jossey-Bass.

Murray, B. G. (2001). Are ecological and evolutionary theories scientific. Biological Reviews, 76(2), 255-289.

Nigg, C. R., Allegrante, J. P., \& Ory, M. (2002). Theory-comparison and multiple-behavior research: common themes advancing health behavior research. Health Education Research, 17, 670-679. 
Nilsen, P. (2015). Making sense of implementation theories, models and frameworks. Implementation Science, 10, 53.

Noar, S. M., Benac, C. N., \& Harris, M. S. (2007). Does tailoring matter? meta-analytic review of tailored print health behavior change interventions. Psychological Bulletin, 133(4), 673.

Noar, S. M., \& Zimmerman, R. S. (2005). Health behavior theory and cumulative knowledge regarding health behaviors: are we moving in the right direction. Health Education Research, 20(3), 275-290.

Norman, P., \& Brain, K. (2005). An application of an extended health belief model to the prediction of breast self-examination among women with a family history of breast cancer. $\mathrm{Br} J$ Health Psychol, 10(Pt 1), 1-16.

Norman, P., \& Conner, M. (2006). The theory of planned behaviour and binge drinking: assessing the moderating role of past behaviour within the theory of planned behaviour. British Journal of Health Psychology, 11(Pt 1), 55-70.

Norman, P. (2011). The theory of planned behavior and binge drinking among undergraduate students: assessing the impact of habit strength. Addictive Behaviors, 36(5), 502-507.

Ogden, J. (2003). Some problems with social cognition models: A pragmatic and conceptual analysis. Health Psychology, 22(4), 424.

Peskin, M. F., Hernandez, B. F., Gabay, E. K., Cuccaro, P., Li, D. H., Ratliff, E. et al. (2017). Using intervention mapping for program design and production of iCHAMPSS: an online decision support system to increase adoption, implementation, and maintenance of evidence-based sexual health programs. Frontiers in Public Health, 5, 203.

Popper, K. (2014). Conjectures and Refutations: The Growth of Scientific Knowledge. New York: Routledge.

Popper, K. R. (1994). The Myth of the Framework: in Defense of Science and Rationality. London: Routledge.

Pot, M., Ruiter, R. A. C., Paulussen, T. W. G. M., Heuvelink, A., de Melker, H. E., van Vliet, H. J. A. et al. (2018). Systematically developing a web-based tailored intervention promoting HPVvaccination acceptability among mothers of invited girls using intervention mapping. Frontiers in Public Health, 6.

Potochnik, A., Colombo, M., \& Wright, C. (2018). Recipes for Science: An Introduction to Scientific Methods and Reasoning. Routledge.

Prestwich, A., Sniehotta, F. F., Whittington, C., Dombrowski, S. U., Rogers, L., \& Michie, S. (2014). Does theory influence the effectiveness of health behavior interventions? meta-analysis. Health Psychology, 33(5), 465.

Project MATCH Research Group. (1998). Therapist effects in three treatments for alcohol problems. Psychotherapy Research, 8(4), 455-474.

Pulido, C., Brown, S. A., Cummins, K., Paulus, M. P., \& Tapert, S. F. (2010). Alcohol cue reactivity task development. Addictive Behaviors, 35(2), 84-90.

Raven, P. H., \& Axelrod, D. I. (1974). Angiosperm biogeography and past continental movements. Annals of the Missouri Botanical Garden, 61(3), 539-673.

Reback, C. J., Fletcher, J. B., Shoptaw, S., \& Mansergh, G. (2015). Exposure to theory-driven text messages is associated with HIV risk reduction among methamphetamine-using men who have sex with men. AIDS and Behavior, 19(2), 130-141.

Rosenstock, I. M., Strecher, V. J., \& Becker, M. H. (1988). Social learning theory and the health belief model. Health education quarterly, 15(2), 175-183.

Rothman, A. J. (2004). "Is there nothing more practical than a good theory?": Why innovations and advances in health behavior change will arise if interventions are used to test and refine theory. International Journal of Behavioral Nutrition and Physical Activity, 1, 11.

Rothman, A. J. (2011). Be prepared: capitalizing on opportunities to advance theory and practice. Journal of Public Health Dentistry, 71 Suppl 1, S49-50. 
Smedslund, G. (2000). A pragmatic basis for judging models and theories in health psychology: The axiomatic method. Journal of Health Psychology, 5(2), 133-149.

Sniehotta, F. F., Presseau, J., \& Araújo-Soares, V. (2014). Time to retire the theory of planned behaviour. Health Psychology Review, 8(1), 1-7.

Staley, K. W. (2014). An Introduction to the Philosophy of Science. Cambridge, UK: Cambridge University Press.

Taylor, N., Conner, M., \& Lawton, R. (2012). The impact of theory on the effectiveness of worksite physical activity interventions: a meta-analysis and meta-regression. Health Psychology Review, 6(1), 33-73.

Thompson, P. (1989). The Structure of Biological Theories. SUNY Press.

Trafimow, D. (2015). Rational Actor Theories. In B. Gawronski \& G. V. Bodenhausen (Eds.), Theory and Explanation in Social Psychology (pp. 245-267). New York: Guilford Publications.

Wacker, J. G. (1998). A definition of theory: research guidelines for different theory-building research methods in operations management. Journal of Operations Management, 16(4), 361385.

Winther, R. G. (2018). The structure of scientific theories. The Stanford Encyclopedia of Philosophy (Winter 2018 Edition) Retrieved October 24, 2018, 2018, from https://plato.stanford.edu/entries/structure-scientific-theories/. 
Table 1. Desiderata of archetypical hypothetico-deductive Theory

\begin{tabular}{|c|c|c|c|c|c|c|c|}
\hline \multirow[b]{2}{*}{ Source } & \multicolumn{6}{|c|}{ Characteristics of Theory } & \multirow{2}{*}{$\begin{array}{c}\text { Exemplar } \\
\begin{array}{c}\text { Theory of Planned } \\
\text { Behavior }\end{array}\end{array}$} \\
\hline & $\begin{array}{l}\text { Glanz, Rimer, } \\
\text { Viswanath, } \\
2015\end{array}$ & $\begin{array}{l}\text { Michie, West, Campbell, } \\
\text { Brown, \& Gainforth, } 2014\end{array}$ & $\begin{array}{c}\text { Colyvan \& } \\
\text { Ginzburg, } \\
2003\end{array}$ & Achinstein, 1968 & $\begin{array}{c}\text { Flyvbjerg, } \\
2001\end{array}$ & Authors' Synthesis & \\
\hline Field & $\begin{array}{c}\text { Health } \\
\text { Promotion }\end{array}$ & $\begin{array}{c}\text { Health } \\
\text { Promotion }\end{array}$ & Ecology & Philosophy & Social Science & Interdisciplinary & Health Promotion \\
\hline \multirow{12}{*}{ 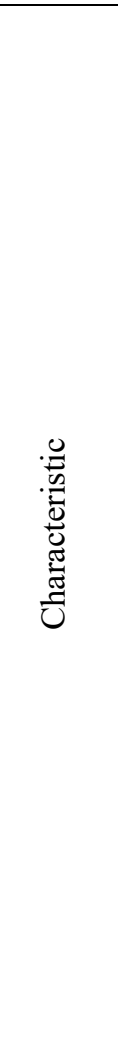 } & Explanatory & Explanatory & Explanatory & $\begin{array}{c}\text { Imparts } \\
\text { Understanding }\end{array}$ & Explanatory & Unificatory $¥$ & Moderate \\
\hline & & & & $\begin{array}{l}\text { Propositions } \\
\text { explicit }\end{array}$ & Explicit & Propositions explicit & Moderate \\
\hline & Predictive & Predictive & Predictive & & Predictive & Predictive & Low \\
\hline & & & & & Complete & Complete & Low \\
\hline & $\begin{array}{l}\text { "No topic } \\
\text { area" }\end{array}$ & & & $\begin{array}{l}\text { Applicable } \\
\text { context* }\end{array}$ & & Delineated & Low \\
\hline & & & Fruitful & & & & High \\
\hline & & & & Nonderivative & & Nonderivative & High \\
\hline & & & & Elemental & & Elemental & Low \\
\hline & Testable & Testable* & Falsifiable & & Falsifiable* & Refutable & Low \\
\hline & & & & $\begin{array}{l}\text { Believed might be } \\
\text { true; } \\
\text { Not known to be } \\
\text { false }\end{array}$ & & $\begin{array}{c}\text { Potential to be } \\
\text { considered } \\
\text { approximately true }\end{array}$ & Low \\
\hline & Generality & Generalizable* & & & Universal & Universal & High \\
\hline & & & & & Discrete & Discrete & High \\
\hline
\end{tabular}


Theory in Health Promotion

\section{Systematic \\ Clear Relationships*}

Parsimony

Coherent Description

Resulting from Inferences

Integrates Accumulated

Knowledge

recisely aligned. W

Notes: Not all treatments precisely aligned. Where authors were silent on a characteristic the cell was left blank. Characteristics are listed on the same

row where there was substantial overlap. Some terms were modified from an author’s original presentation to aid comparison. ¥ Accommodation of prior known empirical patterns are consolidated with forecasted patterns. *Some characteristics were not explicitly included in authors' listings, but were included in their description of science methodology or related discussions. 